\title{
Growth in R\&D investment holding up
}

\section{But analysts expect effects of financial crisis to be more marked next year.}

Globally, corporate investment in research and development (R\&D) grew more slowly in 2008 than in 2007, but remained relatively robust despite the economic crisis, according to a new report by the European Commission.

The 2009 European Union (EU)

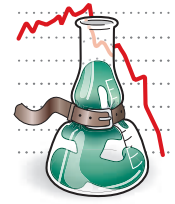

RECESSION

WATCH and medium-tech in Europe and the United States has increased," says Ben Martin, professor of science and technology policy studies at the University of Sussex, UK. Contributing factors, he says, might include the increased pressures of globalization and competition, which often force countries to focus on the industries in which they already have an advantage.

Growing specialization could ultimately reverse the EU's overall lead in investment spending growth, says Hollanders, adding that "there are some concerns that there are not enough firms in R\&D-intensive sectors in Europe". Switzerland, one of the most high-intensity R\&D countries outside the EU and the United States, continues in its leading position, and its investment is growing faster than that of the EU - in part because of its main companies' specialization in the pharmaceutical and biotechnology sectors, he says.

Although the report highlights the fact that growth in R\&D investment remained at a reasonable pace in Europe and the United States in 2008 , it notes that R\&D intensity - defined as the investment by a company in R\&D divided by its net sales - has effectively flatlined in firms in both regions over the past couple of years (see graph). Europe's lack of progress in this area makes it unlikely that it will fulfil the strategy outlined at the 2000 Lisbon summit, which committed member states to an R\&D target of $3 \%$ of national gross domestic product by 2010 .

"It's clear that the Lisbon target was never more than fanciful," Martin says. "It could only have been achieved if industry as well as government rapidly increased the amount of $\mathrm{R} \& \mathrm{D}$ spending."

In another development that could ultimately shift regional balances, companies from emerging economies registered some of the highest $\mathrm{R} \& \mathrm{D}$-investment growth rates despite accounting for a small share of total R\&D. For instance, China posted an R\&D growth rate of $40 \%$, and India $27.3 \%$. "These countries are rapidly becoming top players in R\&D," says Martin.

Hollanders, however, is more sceptical. "They are growing fast," he says, "but if you look at the levels they are coming from, even if the growth records are accurate, it will take a long time before they come up to the level of the EU or the United States."

Although the pharmaceusity-MERIT training centre in Maastricht, the Netherlands. ance of European companies masked some more disquieting indicators for the EU. For ing in 'medium-intensity' sectors, such as automobiles and parts, electronic and electrical equipment and chemicals, with the United States leading in 'high-intensity' R\&D sectors, such as pharmaceuticals, biotechnology and information technology. That remains the case - but it is more marked than in the past.

"I was intrigued that the gap between high-tech

\section{are concerns th enot enough firms in R\&D-intensive ope."}

tical, biotechnology and information-related sectors continued to dominate investment growth in both the EU and the United States, the automotive sector remained surprisingly strong, with car makers forming four of the top ten global R\&D companies by total investment (see chart).

The scoreboard analysis includes only companies with publicly available audited accounts, and that itemize R\&D expenditure in their financial reports, and it assigns companies to the country of their registered office, even if R\&D operations are located in a different region.

\section{Andrea Chipman}
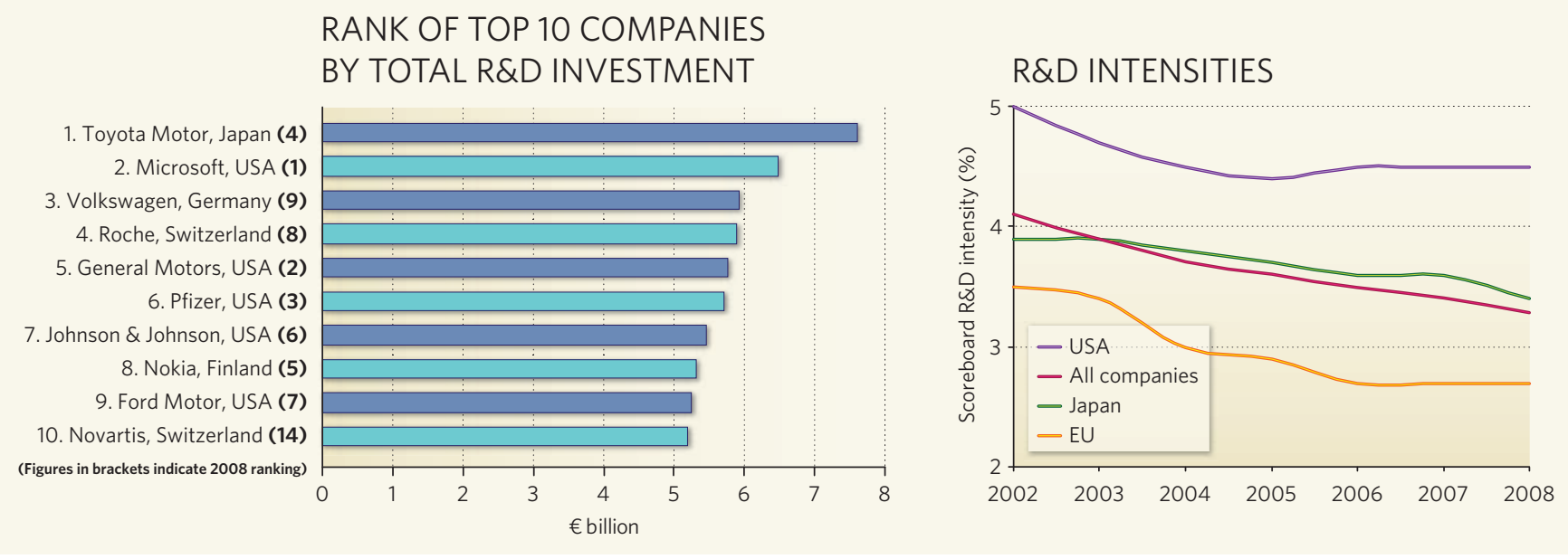